\title{
THE IMPACT OF A WIND POWER PLANT WITH DOUBLY FED INDUCTION GENERATOR ON THE POWER SYSTEMS
}

\author{
Trinh Trong Chuong \\ HaNoi University of Idustry \\ (Manuscript Received on July $27^{\text {th }}, 2009$, Manuscript Revised December $12^{\text {st }}, 2010$ )
}

ABSTRACT: In this paper the effect of the wind power plants with Double Fed Induction Generator (DFIG) on the electric power system operation is investigated. The important characteristics such as: voltage quality, grid voltage stability, active and reactive loss of a DFIG at different fault conditions are studied. The simulation results clealy show the effect of the wind power plants on the grid voltage stability and power quality of electric power system.

Keywords: the wind power plants , DFIG, electric power system.

\section{INTRODUCTION}

As a result of conventional energy sources consumption and increasing environmental concern, efforts have been made to generate electricity from renewable sources, such as wind energy sources. Institutional support on wind energy sources, together with the wind energy potential and improvement of wind energy conversion technology, has led to a fast development of wind power generation in recent years. Other reasons could be the fuel price but especially environmental demands. The wind generation does not pollute the surrounding areas and also does not produce waste products. To get the maximum possible power, the wind generator speed should change according to the wind speed.

Generally the WTs (WTs) can either operate at fixed speed or variable speed. For a fixed speed WT the generator is directly connected to the electrical grid. The rotor speed of the fixed speed WT is in principle determined by a gearbox and the pole-pair number of the generator. An impediment of the fixed speed WT is that power quality of the output power is poor. For a variable speed WT equipped with a converter connected to the stator of the generator, the generator could either be a cage bar induction generator, synchronous generator or permanent-magnet synchronous generator. There are several reasons for using variable-speed operation of WTs; among those are possibilities to reduce stresses of the mechanical structure, acoustic noise reduction and the possibility to control active and reactive power [1]. An important type of variable speed WT is WT with DFIG. This means that the stator is directly connected to the grid while the rotor winding is connected via slip rings to a back-to-back converter (Fig.1). Today, DFIG are commonly used by the WT industries for larger WTs [2]. The major advantage of the DFIG, which has made 
it popular, is that the power electronic equipment only has to handle a fraction (20$30 \%$ ) of the total system power [3]. This means that the cost of the power electronic equipment and the losses in the equipment can be reduced in comparison to power electronic equipment that has to handle the total system power as for a direct-driven synchronous generator, apart from the cost saving of using a smaller converter [4]. The rest of this paper is organized as follows: section 2 describes DFIG model consist of turbine, drive train, pitch controller, generator, converter controller models. Section 3 explains the study system. The results of simulation are presented in section 4. Conclusions are finally made in section 5 .

\section{WIND TURBINE WITH DFIG}

For variable speed systems with limited variable-speed range $( \pm 30 \%$ of synchronous speed), the DFIG can be a cost effective solution. The DFIG converter consists of two converters that are connected "back-to-back" as in Fig 1; machine-side converter and grid side converter. Between the converters a dc-link capacitor is placed, as energy storage to keep the dc-link voltage variations (or ripple) small. With the machine-side converter it is possible to control the torque or the speed of the DFIG and also the power factor at the stator terminals, while the main objective for the grid-side converter is to keep the dc-link voltage constant. The speed-torque characteristics of the DFIG system can be seen in Fig $2[3,5]$. As also seen in the figure, the DFIG can operate both in motor and generator operation with a rotor-speed range of $\pm \Delta \omega_{\mathrm{r}} \max$ around the synchronous speed.

\subsection{WT-DFIG Model Description}

The complete model of a WT-DFIG is constructed from a number of sub models, i.e. a) turbine, b) drive train, c) pitch controller, d) wound-rotor induction generator, e) rotor-side converters. The general structure of the model is in Fig.1.

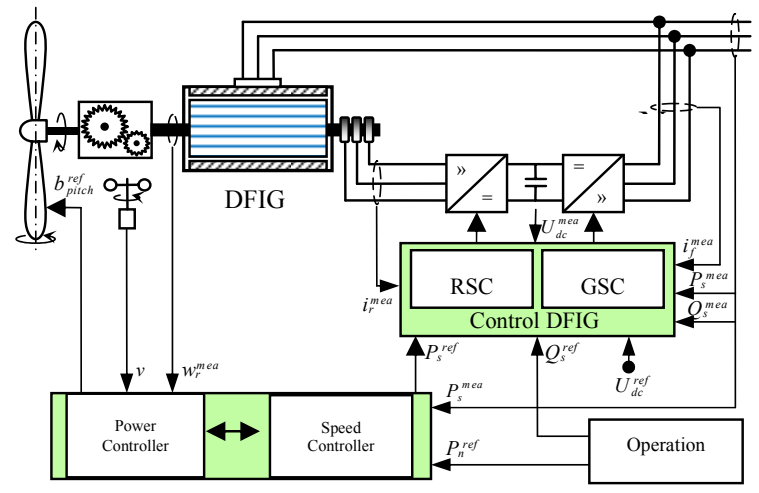

Figure 1. General structure of the DFIG 


\subsection{Turbine model}

One common way to control the active power of a WT is by regulating the $\mathrm{C}_{\mathrm{p}}$ value of the rotor turbine. In the model, the $\mathrm{C}_{\mathrm{p}}$ value of the turbine rotor is approximated using a nonlinear function according to (2) [5].

$$
\begin{aligned}
& P_{m}=\frac{1}{2} \rho A_{T} C_{P}(\lambda, \beta) \cdot v_{\text {wind }}^{3} \\
& C_{P}(\lambda, \beta)=0.22\left(\frac{116}{\lambda_{i}}-0.4 \beta-5\right) \cdot e^{-\frac{12.5}{\lambda_{i}}} \\
& \frac{1}{\lambda_{i}}=\frac{1}{\lambda+0.008 \beta}-\frac{0.035}{\beta^{3}+1}
\end{aligned}
$$

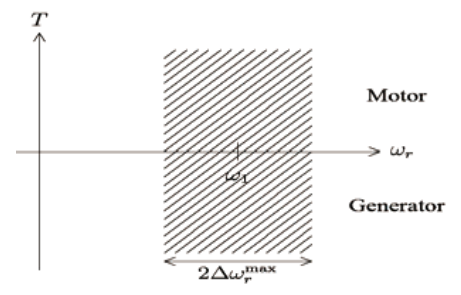

Figure 2. Speed-torque characteristics of a DFIG

Where $C_{p}$ is the power coefficient, $\beta$ is the pitch angle, $\lambda$ is the tip speed ratio, $\omega_{\text {wind }}$ is the wind speed, $\omega_{\mathrm{r}}$ is the rotor speed, $\mathrm{r}_{\mathrm{r}}$ is the rotorplane radius, $\rho$ is the air density and $A_{r}$ is the area swept by the rotor.

\subsection{Drive-train model}

When investigating dynamic stability, it is important to include the drive-train system of a WT in the model. Its model consists of two main masses; the turbine mass and generator mass (Fig.3). These are connected to each other via a shaft that has certain stiffness and damping constant values. The equation of the turbine side is given as:
$2 H_{t} \frac{d \omega_{t}}{d t}=T_{t}-K_{s} \cdot \theta_{t g}-D_{s} \cdot\left(\omega_{t}-\omega_{g}\right)$

$2 H_{g} \frac{d \omega_{g}}{d t}=T_{g}+K_{s} \cdot \theta+D_{s} \cdot\left(\omega_{t}-\omega_{g}\right)$

$\frac{d \theta_{t g}}{d t}=\omega_{\text {base }}\left(\omega_{t}-\omega_{g}\right)$

Where $\mathrm{H}$ is the inertia constant, $\mathrm{T}$ is torque and $\omega$ is angular speed. Subscripts $g$ and $t$ indicate the generator and turbine quantities, respectively. The shaft stiffness and damping constant value are represented in $K_{S}$ and $D_{S}$, $\omega_{\text {base }} \mathrm{s}$ in the base value of angular speed [3].

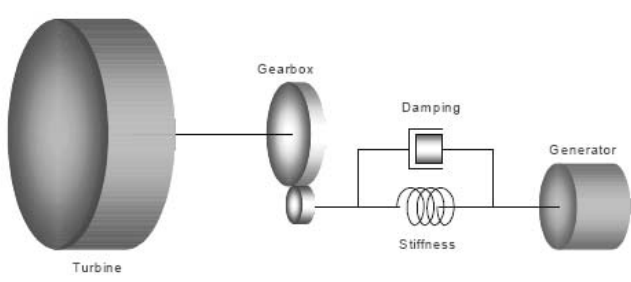

Figure 3. Drive- Train system of WT-DFIG.

\subsection{Pitch controllermodel}

According to equation (2), the cp value can be reduced by increasing the pitch angle $\beta$. However, the pitch angle is not able to reach the set point value immediately. Accordingly, for a more realistic simulation, a rate limiter is implemented in the pitch controller model.

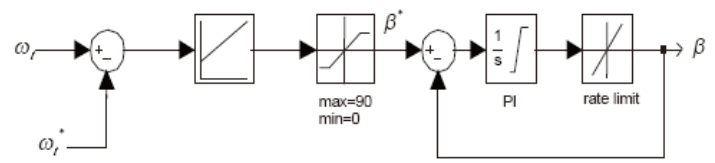

Figure 4. Pitch controller diagram

The pitch-angle controller block diagram, shown in Fig.4, is employed to limit the rotor speed. For this reason, the pitch-angle 
controller is active only during high average wind speed [3].

\subsection{Generatormodel}

The generator is basically a slip-ring induction machine, which can be modeled according to [1] by the following equations.

$u_{s}=R_{s} \cdot i_{s}+\frac{d}{d t}\left(\psi_{s}\right)+\left(\omega_{a}-\omega_{s}\right) \psi_{s}$

$u_{r}=R_{r} i_{r}+\frac{d}{d t}\left(\psi_{r}\right)+\left(\omega_{a}-\omega_{r}\right) \psi_{r}$

where $\mathrm{u}, \mathrm{i}$ and $\psi$ are vectors of voltage, current and flux those are functions of time, and $\mathrm{R}$ is the resistance. Subscripts $\mathrm{s}$ and $\mathrm{r}$ denote the stator and rotor quantities. The speed of the rotor is denoted by $\omega_{\mathrm{r}}$. The equations are given in an arbitrary reference frame, which rotates at arbitrary speed of $\omega_{\mathrm{a}}$. The flux and current relations are given as:

$\psi_{s}=\left(L_{s l}+L_{m}\right) \cdot i_{s}+L_{m} \cdot i_{r}$ $\psi_{r}=\left(L_{r l}+L_{m}\right) \cdot i_{r}+L_{m} \cdot i_{s}$

where $\mathrm{L}_{\mathrm{m}}$ is the mutual inductance and $\mathrm{L}_{\mathrm{sl}}$ and $\mathrm{L}_{\mathrm{rl}}$ are the stator and rotor leakage inductances, respectively.

\subsection{The rotor side converters controllermodel}

The rotor side converter is modeled as a voltage source type. For simplification, switching phenomena and dynamic limitations in the converter are neglected by assuming that switching frequency is infinite. The purpose of the controller is to regulate the active and reactive power output independently. To decouple these two parameters, generator quantities are calculated using vector control in a synchronous reference frame fixed to the stator flux. The controller provides set point values of the quadrature and direct axis component of the rotor current $\left(i_{\mathrm{qr}}\right.$ and $\left.\mathrm{i}_{\mathrm{dr}}\right)$. The active power is controlled as shown in Figure 5 [3]. A generic model of the voltage and reactive power control is arranged in a cascaded mode as shown in Figure 6 [3].

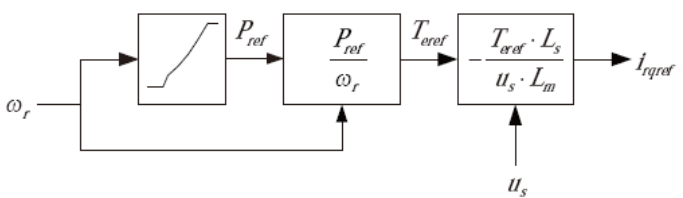

Figure 5. Active power control diagram

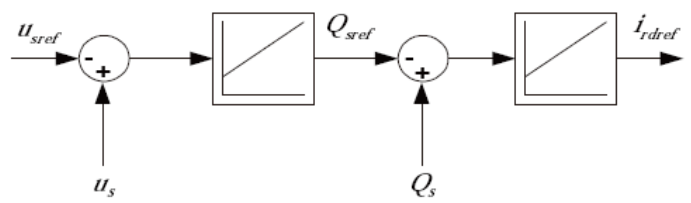

Figure 6. Reactive power and voltage control diagram

The DFIG can be operated to implement, either constant reactive power control, or controlled terminal voltage. In this paper, the first method is employed.

\section{SYSTEM UNDER STUDY}

The studied model represents an equivalent of the PhuocNinh, NinhThuan, Vietnam (Fig. 7) system in the area where large scale wind power production is located [6]. The model represents a 20MW wind power station consisting 10 turbines with DFIG connected to the grid. The turbines are stall regulated type, with a rating of $2.0 \mathrm{MW}$ each. Fig 8 shows the equivalent model of the system. $Z_{\mathrm{th}}=(0,00125$ 
$+\mathrm{j} 0.005)$ [7]. Sending end voltage is constant.

In order to investigate the impact of the injection of active power by the Wind power plant (WP) the system is approximated to a series of impedances as indicated below.

\section{SIMULATION}

To investigate the impact of operating the WT-DFIG on the power grid, two configurations are distinguished: i) grid and load alone, and ii) grid, load and WP. The important characteristics, such as voltage profile, load bus PV characteristic, active power losses, and also transient stability at no load, full load and different fault conditions (three phase symmetrical short circuit and one phaseto- ground short circuit) are studied for connected and unconnected WP operation.

\subsection{Steady State Voltage Profile}

The steady-state voltage profile for two different conditions are simulated, a) WP connected at wind speeds of $4 \mathrm{~m} / \mathrm{s}, 8 \mathrm{~m} / \mathrm{s}, 12$ $\mathrm{m} / \mathrm{s}$ (nominal generation), and $20 \mathrm{~m} / \mathrm{s}$, and $\mathrm{b}$ )
WP is not connected. Load bus voltage at non presence of WP bus, is represented in (5) and (6).

$$
\begin{aligned}
& U_{\text {load_bus }_{-}}=\cos \theta \cdot U_{\text {grid }}-j Z_{c} \sin \theta \cdot I_{\text {grid }} \\
& I_{\text {grid }}=\frac{P_{\text {grid }}-j Q_{\text {grid }}}{U_{\text {grid }}}
\end{aligned}
$$

From equations (11) and (12):

$$
\begin{aligned}
& U_{\text {load_bus }}=\left[\cos \theta-j P_{\text {grid }}^{*} \cdot \sin \theta-Q_{\text {grid }}^{*} \cdot \sin \theta\right] U_{\text {grid }} \\
& \text { With } \quad P_{\text {grid }}^{*}=\frac{P_{\text {grid }}}{P_{c}} ; \quad Q_{\text {grid }}^{*}=\frac{Q_{\text {grid }}}{P_{c}}
\end{aligned}
$$

where $U_{\text {loadbus }}$ is the loadbus voltage, $\theta$ is the wave length. $\mathrm{Q}_{\text {grid }}, \mathrm{P}_{\text {grid }}$ are the grid reactive and active powers respectively, $\mathrm{P}_{\mathrm{c}}$ is the natural power, $U_{\text {grid }} V$ is the grid voltage and $Z_{c}$ is the natural impedance. By considering equation (6), if $\mathrm{Q}_{\text {grid }}^{*}$ or $\mathrm{P}_{\text {grid }}^{*}$ reduce, $\mathrm{U}_{\text {loadbus }}$ will improve.

Figure 7 shows the simulation results. The WP bus injects the active and reactive power to the load bus and improves the load-bus voltage. By increasing the wind speed, the $U_{\text {loadbus }}$ improvement is greater.

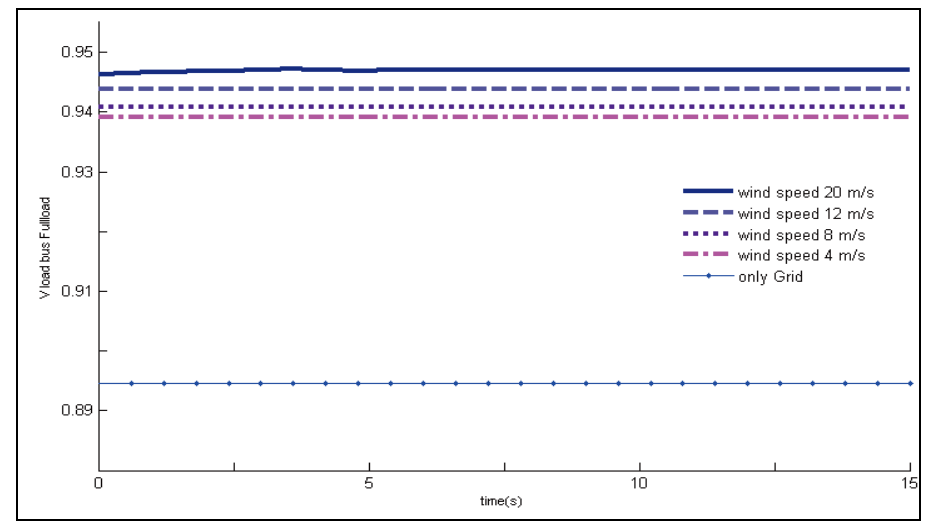

Figure 7. Steady-state voltage profile for conditions (a) and (b) 


\subsection{Voltage stability (PV characteristics)}

This first option investigates the possibility of using this transformer to handle the WP. This layout is shown below. Note that, for the purposes of this type of analysis, the WP is modelled by combining all the WTs into one. The transformer that is normally located at the base of each machine is, therefore, also combined into one item [7].

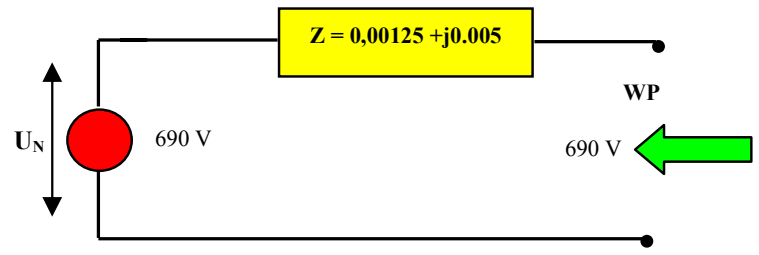

Fig 8. Equivalent grid and connection system impedance as seen from the low voltage (690V)

For this option the voltage profile at the generator terminals is required and therefore all the impedances need to be reflected to the voltage level at the generator, i.e. $690 \mathrm{~V}$. This calculation is worked through in the sections that follow. In order to investigate the impact of the injection of active power by the WP the system is approximated to a series of impedances as indicated below.
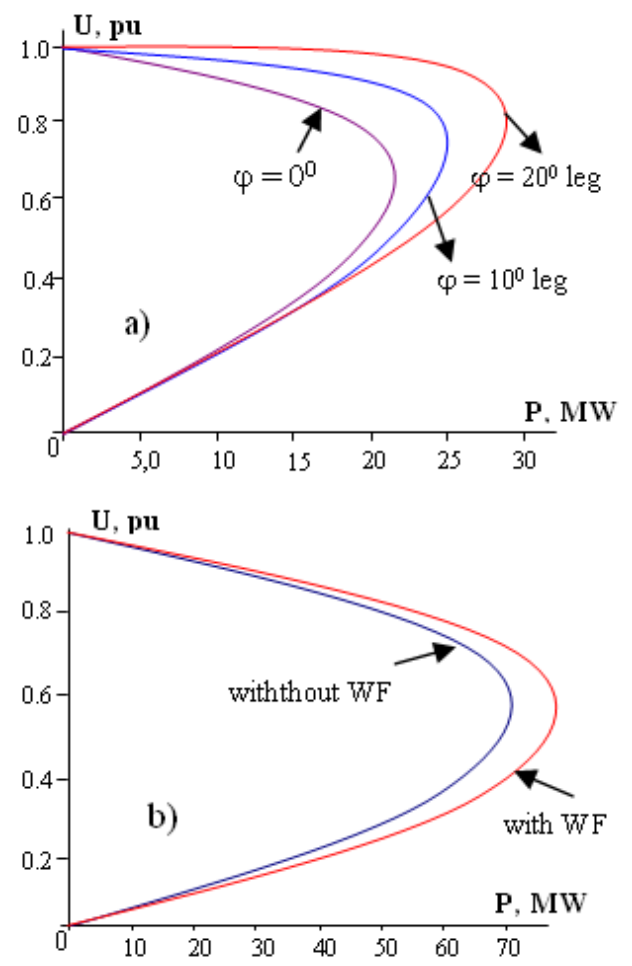

Fig.9. PU characteristics at PCC and under connected- unconnected WP conditions 
In Fig $8, Z_{\text {th }}$ is the Thevenin equivalent impedance of the grid up to the PCC and the connection equipment up and until the point being considered. The impedance is composed of both resistance $\left(\mathrm{R}_{\mathrm{th}}\right)$ and reactance $\left(\mathrm{X}_{\mathrm{th}}\right)$. In mathematical terms, the resistance is a real number and the reactance an imaginary number, hence it is " $\mathrm{j} \mathrm{X}_{\mathrm{th}}$ ". This is the impedance that represents the WPP. The resistive (real, $\mathrm{R}_{\mathrm{WF}}$ ) component is negative so that current and hence active power is produced. If there is anything but full power factor compensation, the reactive (imaginary, $\mathrm{j} \mathrm{X}_{\mathrm{WF}}$ ) component is positive such that the current through and voltage across the impedance are out of phase and reactive power is consumed. For this option the voltage profile at the generator terminals is required and therefore all the impedances need to be reflected to the voltage level at the generator. Fundamentally, it simulates the injection of current from the WPP in steps and calculates the voltage dropped across the Thevenin impedance at each step. This builds up number of points for the voltage at the generator terminals as the power injected increases.

The PU curves for the above problem has been drawn for $0^{\circ}, 10^{\circ}$ leading and $20^{\circ}$ leading power factor angle. From the curve we obtain that value of $\mathrm{P}_{\mathrm{L}}$ increases from lagging to leading power factor. We also obtain that there are two values of $\mathrm{U}_{\mathrm{L}}$ for a given $\mathrm{P}_{\mathrm{L}}$ except at $P_{\text {Lmax }}$. The curves is shown in Fig. 9. This graph shows that, following the $\mathrm{pf}=1$ from left to right, the voltage rises as the current injected increases and the power increases to about 21,3 MW. Then after 21,3 MW the voltage starts to drop until the critical point where the rate of decrease in voltage is faster than the rate of increase in the current injected and the power actually drops. This (the nose point) is the onset of voltage instability. From this it can be seen that i) approximately a maximum of 21,3 MW power can be injected without instability, and ii) reactive power control is necessary so that the WPP can be operated at, or very close to, unity power factor. If the power factor drops, it can be seen that operation is much too close to the point of voltage instability. Furthermore, the basic compensation known as "no-load" compensation is insufficient. What all this means, in practice, is that if the power factor compensation units fail then WP production must be stopped.

\subsection{Line Active Power Losses}

Active power loss in the transmission line can be calculated by the equations (7) to (8).

$P_{\text {loss_line }}=3 . Z_{\text {line }} \cdot\left|I_{\text {grid }}\right|^{2}=3 . Z_{\text {line }} \cdot \frac{\left|P_{\text {grid }}^{2}+Q_{\text {grid }}^{2}\right|}{U_{\text {grid }}^{2}}$

Total active power losses under full-load and no-load conditions at different wind speed $(4,8,12$, and $20 \mathrm{~m} / \mathrm{s})$ are calculated according.

$P_{\text {Total_loss }}=P_{\text {grid }}+P_{\text {DFIG }}-P_{\text {load }}$

Where $\mathrm{P}_{\text {Total Loss }}$ is the total line power losses, $\mathrm{P}_{\text {grid }}$ the grid delivered power, $\mathrm{P}_{\text {DFIG }}$ the WP delivered power and $\mathrm{P}_{\text {load }}$ the power consumed by the load. According to equation (7), any reduction in $\mathrm{P}_{\text {grid }}$ or $\mathrm{Q}_{\text {grid }}$, reduces the 
power losses. This reduction of $\mathrm{P}_{\text {grid }}$ or $\mathrm{Q}_{\text {grid }}$ may be compensated by the WP.

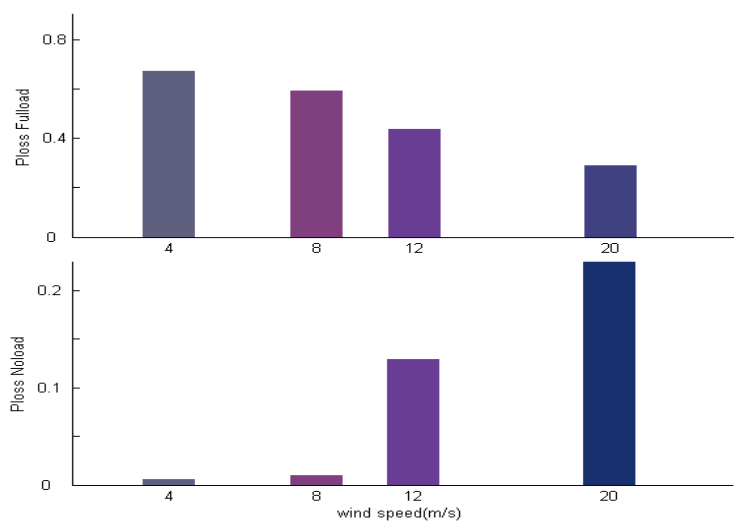

Fig. 10. Active power losses at full load and no-load

Fig. 10 gives simulation results. As the results show, with full-load the active losses reduce when the wind speed increases due to an increasing injected power from the WP. In contrast, with no-load an increasing wind speed raises the losses. The reason for this is the lengthy power transmission lines between the WP and grid (see equation $(7,8)$ ).

\subsection{Transient Stability}

For transient-stability evaluation a series of simulations are performed considering different operating conditions. The following scenarios are examined: i) applying a short-circuit fault that is cleared after $200 \mathrm{~ms}$, ii) connecting and disconnecting load, iii) WT operation under the fault condition, iv) WTs operation for the connected load condition, v) WT operation with disconnection from the WP bus. At $t=5 \mathrm{~s}$, a temporary three phase short-circuit is placed on the load bus. After fault clearing, the load is disconnected from the load bus. The load is connected again at $\mathrm{t}=6.2 \mathrm{~s}$.

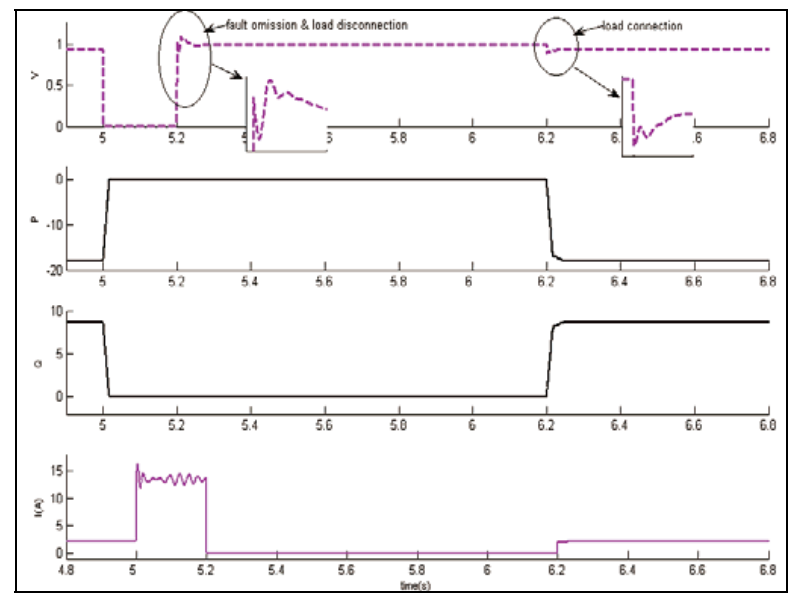

Fig. 11. Three-phase fault on the load bus

Simulation results are shown in figures 11 and 12. During faults all the DFIG turbines have zero outputs; but, after fault clearance, all of them experience short-term motor behavior.
This is due to energy attraction by the turbines. For briefness, only two-turbine behavior is presented in the figures. However, the system becomes stable after a short time.

Trang 53 


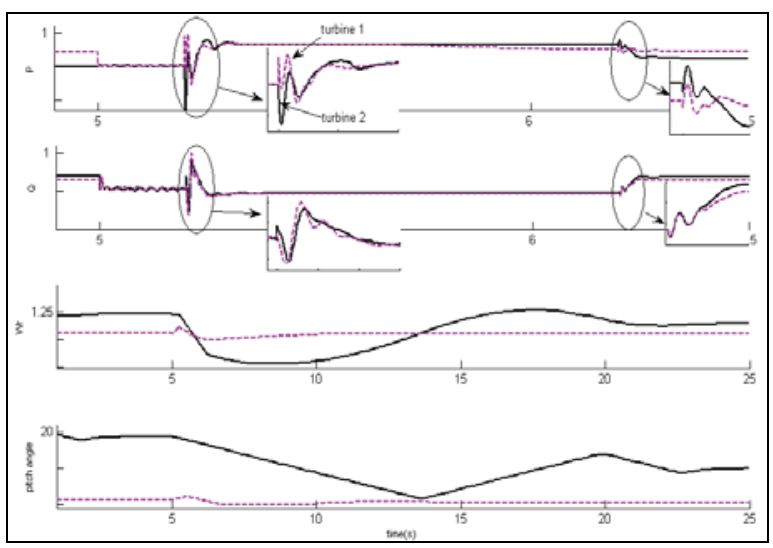

Fig.12. DFIG operation for three-phase fault condition

WTs-DFIG operation during local load connection is also investigated and results are shown at figure 13. This figure consists of the WP voltage, active and reactive power, the rotor speeds of the two turbines, and their pitch angle variations during this condition. The WT rotor speeds as a transient stability indicator show a stable behavior. Finally, figure 15 shows the result when one of the DFIG is disconnected from the WT.

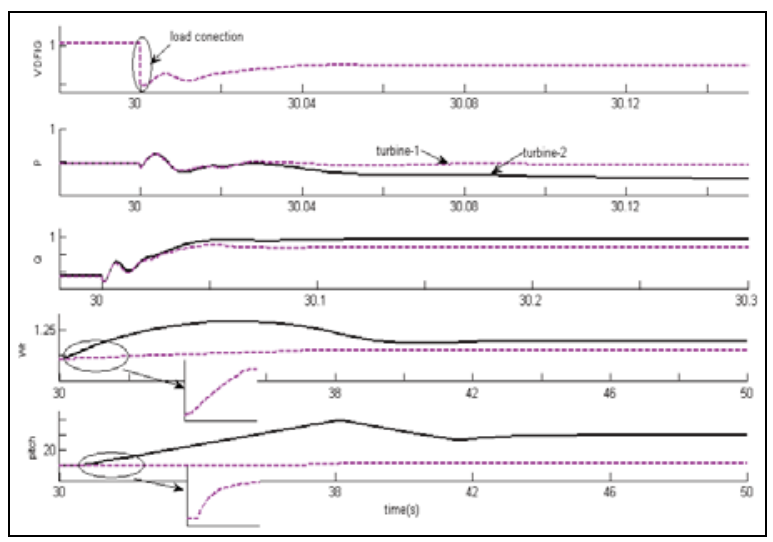

Fig. 13. Turbine disconnection condition

\section{CONCLUSIONS}

The research and simulation results have shown that the DFIG improves the voltage profile and the voltage stability of the load bus. In addition, this impact is confirmed at low wind speed $4 \mathrm{~m} / \mathrm{s}$ (low generation). During faults all the DFIG turbines have zero outputs; but after fault clearance all of them experience short-term motor behavior; however the system remains stable after that. In general, the connection of DFIGs improve the stability of the system and the load voltage. Wind power generation with DFIG provides better performance for terminal-voltage recovery after the load connects suddenly.

\section{Trang 54}




\section{ẢNH HƯởNG CỦA NHÀ MÁY ĐIỆN GIÓ SỬ DỤNG MÁY ĐIỆN KHÔNG ĐỒNG Bộ NGUỒN KÉP ĐẾN CÁC HỆ THỐNG ĐIỆN}

\section{Trịnh Trọng Chưởng}

Trường Đại học Công nghệ Hà Nội

TÓM TÄT: Bài báo này nghiên cưu ảnh hưởng của nguồn điện gió sủ dụng loại máy phát không đồng bộ nguồn kép (DFIG) đến chế độ vận hành của hệ thống điện. Nội dung đề cập chủ yếu bao gồm các vấn đề về chất lượng điện áp, đặc tính ổn định điện áp nút kết nối, tổn thất công suất tác dụng cũng nhu phản ứng của máy phát khi có các sụ cố ngắn mach tại điểm kết nối chung-PCC. Kết quả mô phỏng sẽ mô tả một cách rõ nét các ảnh hưởng của nguồn điện gió đến ổn định điện áp và chất luợng điện năng của hệ thống điện.

Tù khóa: nhà máy điện gió, DFIG, hệ thống điện.

\section{REFERENCES}

[1]. Francoise Mei, and Bikash C. Pal, Modelling and Small-Signal Analysis of a Grid Connected Doubly-Fed Induction Generator; IEEE Trans. on Power Sytstems, vol. 18, pp.803-809, (May 2005).

[2]. Joris Soens, Impact of Wind Energy in a Future Power Grid, PhD thesis, Katholieke Universiteti Leuven, Leuven, (May 2005).

[3]. Johannes Gerlof SLOOTWEG, Wind Power: Modelling and Impact on Power System Dynamics, PhD thesis Technische Universiteit Delft, (2003).

[4]. James D. Bailey, Factors influencing the protection of small-to-medium size induction generators, IEEE Transactions on Industry applications, Vol.24, No.5, (September 1988).

[5]. Tony Burton, David Sharpe, Nick Jenkins, Ervin Bossanyi, Wind Energy Handbook, John Wiley \& Sons Ltd, Reprinted, (March 2004).

[6]. RISØ, Feasibility Assessment and Capacity Building for Wind Energy Development in Cambodia, Philippines and Vietnam, (November 2006).

[7]. Trinh Trong Chuong, Voltage stability analysis of grid connected wind generators, International Conference on Electrical Engineering, Japan, (2008). 